\title{
ОСТРЫЙ КАЛЬКУЛЁЗНЫЙ ХОЛЕЦИСТИТ ЭТИОПАТОГЕНЕЗ, КЛАССИФИКАЦИЯ, КЛИНИКА (ЛЕКЦИЯ)
}

\section{ACUTE CALCULOUS CHOLECYSTITIS ETIOPATHOGENESIS, CLASSIFICATION, CLINIC (LECTURE)}

\author{
A. Yashnov \\ O. Konovalova \\ J. Hanina \\ M. Burtseva \\ E. Passonen
}

Summary. Acute calculous cholecystitis, as one of the most dangerous complications of cholelithiasis, remains an urgent and not fully understood problem of emergency abdominal surgery. It should be noted that acute calculous cholecystitis, according to Russian scientists, is diagnosed in every second patient with calculous cholecystitis. This article reflects the latest information about the etiopathogenesis of cholelithiasis. Two main theories of the occurrence of cholelithiasis are revealed. The main mechanisms of the pathogenesis of acute calculous cholecystitis are described. The full clinical picture of this pathology, with the main syndromes of the disease, is presented. At the same time, the main methods of laboratory and intsrumental diagnostics are disclosed. All diagnostic methods are described with a reflection of the advantages of performing for the diagnosis of this pathology. The article reflects modern methods of treatment of acute calculous cholecystitis with a description of the advantages and disadvantages. Thus, the article reflects a sufficient review of the literature on such a serious and significant disease in emergency abdominal surgery as acute calculous cholecystitis. The article serves as a full-fledged source of information collected using the research of both domestic and foreign scientists.

Keywords: gallstone disease, cholelithiasis, acute calculous cholecystitis, etiology and pathogenesis of cholelithiasis, the diagnosis of acute cholecystitis treatment of acute cholecystitis.

\section{Актуа^ьность}

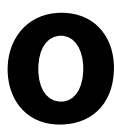
стрый калькулёзный холецистит, как одно из наиболее грозных осложнений желчнокаменной болезни, остаётся актуальной и до конца не изученной проблемой неотложной абдоминальной хирургии. По данным зарубежных авторов распро-
Яшнов Алексей Александрович

К.м.н. ассистент, ФГБОУ ВО «Читинская государственная медицинская академия» alexyashnov@mail.ru

Коновалова Ольга Геннадьевна

К.м.н. дочент, ФГБОУ ВО «Читинская государственная медицинская академия»

Ханина Юлия Сергеевна

К.м.н. дочент, ФГБОУ ВО «Читинская государственная медицинская академия»

Бурцева Мария Александровна ГУЗ «Городская клиническая больнича № 1» 2. Чита

Пассонен Екатерина Юрьевна

Врач-хирург, ГУЗ «Городская клиническая больнича № 1» 2. Чuma

Аннотация. Острый калькулёзный холецистит, как одно из наиболее грозных осложнений желчнокаменной болезни, остаётся актуальной и до конца не изученной проблемой неотложной абдоминальной хирургии. Необходимо отметить, что острый калькулёзный холецистит, по данным отечественных ученных диагностируется у каждого второго больного с калькулёзным холециститом. В данной статье отражены последние сведения об этиопатогенезе желчнокаменной болезни. Раскрыты две основные теории возникновения холелитиаза. Отражены основные механизмы патогенеза острого калькулёзного холецистита. Представлена полная клиническая картина данной патологии, с основными синдромами заболевания. Вместе с тем, раскрыты основные методы лабораторной и инструментальной диагностики. Все диагностические методы расписаны с отражением преимуществ выполнения для диагностики данной патологии. В статье отражены современные методы лечения острого калькулезного холецистита с описанием преимуществ и недостатков. Таким образом, статья отражает в достаточном объеме обзор литературы по такому серьёзному и значимому заболеванию в неотложной абдоминальной хирургии, как острый калькулёзный холецистит. Статья служит полноценным источником информации, собранным с использованием исследований как отечественных, так и зарубежных ученых.

Ключевые слова: желчнокаменная болезнь, холелитиаз, острый калькулёзный холецистит, этиопатогенез холелитиаза, диагностика острого холецистита, лечение острого холецистита.

страненность желчнокаменной болезни во всем мире разнообразна. Так в США холелитиазом болеют в среднем 4-7\% населения [1,2,3,4]. В Европейских странах частота желчнокаменной болезни составляет 9-20\%, в зависимости от расовой принадлежности. Группа итальянских ученых в своём много централизованном исследовании установила, что холелитиаз чаще наблю- 
дается у представительниц слабого пола и составляет $18,8 \%$, в то время как у мужчин - 9,5\%. Интересен тот факт, что по данным скандинавских ученных, камненосительство встречается у 53\% женщин и $32 \%$ мужчин, проживающих в Скандинавии. При этом в Норвегии установлено, что носителями желчных конкрементов явились 21,2\% лиц слабого пола и 17,7\% - сильного. Жители африканских и азиатских стран менее подвержены развитию холелитиаза. Так по данным японских учёных встречаемость данной патологии в Японии составляет 3,5-5\%. В Российской Федерации распространенность желчнокаменной болезни также колеблется в зависимости от этнической принадлежности в широких пределах. Согласно данным полученным при ультразвуковом обследовании, компьютерной томографии и аутопсии желчные конкременты встречаются от 5 до 25 случаев $[5,6,7,8.9]$.

Необходимо отметить, что острый калькулёзный холецистит, по данным отечественных ученных диагностируется у каждого второго больного с калькулёзным холециститом [10,11]. Вместе с эти, среди пациентов с неотложной хирургической патологией острый калькулёзный холецистит встречается в 13-18\% случаев. Высокая летальность при остром калькулёзном холецистите диктует необходимость искать более рациональные методы своевременной диагностики данного осложнения и разрабатывать наиболее оптимальную тактику ведения таких пациентов. Так летальность при остром калькулёзном холецистите при хирургическом лечении достигает 4-6\% у лиц трудоспособного возраста. Наряду с этим, у лиц преклонного возраста и с тяжелой сопутствующей патологией данный показатель достигает 11-27\% [10,11]. Помимо летальных исходов, в группе прооперированных пациентов наблюдается высокая частота развития послеоперационных гнойно-воспалительных осложнений: подпеченочные абсцессы, желчные свищи, желчный перитонит и другие. Встречаемость данных осложнений варьируется от 6-9\% случаев и приводит к летальному исходу или стойкой потере нетрудоспособности и инвалидизации $[12,13]$.

Первое упоминание о вскрытии подпечёночного абсцесса голландским хирургом Сталпером Ван дер Вилом, который возник вследствие острого калькулёзного деструктивного холецистита, появились в 1687 г. Спустя практически 200 лет Марион Симс выполняет первую успешную холецистостомию. Почетное звание хирурга, который первым в 1882 г. выполнил холецистэктомию принадлежит Карлу Лангенбуху. При этом лишь в 1987 г. французский хирург Филипп Муре производит первую лапароскопическую холецистэктомию. На протяжении последних лет и в настоящее время оперативные вмешательства при остром калькулёзном холецистите выполняются в экстренном или отсроченном периодах заболевания. Наряду с этим, ряд вмешательств выполняется в так называемом «холодном периоде», спустя 6-8 месяцев от появления первых клинических признаков заболевания. Ежегодно во всем мире выполняется в среднем 2,5 млн. холецистэктомий в год. Несмотря на то, что в последние десятилетия хирургами со всего мира достигнуты большие успехи в разработке схем лечения острого калькулёзного холецистита, до настоящего времени сохраняется неудовлетворенность результатами лечения $[12,13,14,15]$.

Этиопатогенез. Этиопатогенез острого калькулёзного холецистита неразрывно связан с причинами возникновения желчнокаменной болезни. В конце XVIII века зарождаются две основные теории возникновения желчнокаменной болезни. Основоположниками первой теории становятся такие выдающие ученные, как Вильгельм Тидичум, Клод Бернар, Ш. Бушар, Д. Бойсен; А. Шауффард; Т. Ровзинг. Они предположили, что литогенез неразрывно связан с патологическими процессами, протекающими в печени, которые способствуют экстракции низменной по составу желчи. Последняя в свою очередь сгущается, происходит выпадение твердых частиц в желчь, что и служит основой камнеобразования. Другие знаменитые ученные того времени (М. Хелмбаш, С.П. Боткин, Б. Наунун) высказывают предположение, что процесс камнеобразования связан с воспалительными процессами в стенке желчного пузыря и гипомоторикой желчного пузыря. Вместе с тем, необходимо отметить, что этиология желчнокаменной болезни до настоящего времени остаётся недостаточно изученной. Наряду с этим причины данного заболевание необходимо рассматривать скорее, как мульти факторные, нежели моноэтиологические $[16,17,18,19]$.

Определенную роль в развитии желчнокаменной болезни и как следствие острого холецистита отводят:

- инфекционному процессу в пищеварительном тракте;

- дуоденобилиарному рефлексу;

> ожирению;

- наследственности;

- литогенной диете;

- полиморфизму определенных генов и др.

В настоящее время выделяют следующие группы конкрементов: холестериновые, пигментные, известковые и смешанные. Холестериновые желчные камни в своём составе содержат наибольшее количество холестерина, зачастую небольшого размера и округлой формы. Следующая группа конкрементов - известковые, в своём составе содержат большое количество солей кальция, что и придаёт им плотную структуру. Пигментные конкременты в свою очередь подразделятся на чёрные и коричневые. Чёрные конкременты преобладают у лиц 
преклонного возраста и в своём составе содержат фосфаты и билирубинаты кальция. Наряду с этим коричневые конкременты в своей структуре состоят из билирубината, пальмитата, стеарата и холестерина. Последняя группа конкрементов смешанные в своём составе представлены разнообразными соотношениями солей билирубина, кальция и холестерина $[20,21]$.

Установлено, что в этиопатогенезе холелитиаза значимы следующие факторы: повышение литогенности желчи, гипомоторика желчного пузыря, повышение давления в билиарном дереве, инфекционный процесс. Вместе с тем, необходимо отметить, что из-за избыточного насыщения желчи холестерином возникают процессы нуклеации. При этом муцин, выделяемый слизистой желчного пузыря фиксирует на себе, выпадшие в осадок кристаллы холестерина, а также взвесь жидких кристаллов. Гипомоторика желчного пузыря способствует процессу преобразованию везикул, насыщенных холестерином в твердые кристаллы. Вместе с тем, на кристаллы холестерина оседают соли кальция, которые могут выполнять и роль ядер кристаллизации холестерина. Помимо этого, гипомотрика желчного пузыря служит предрасполагающим фактором для литогенеза, в виду того, что кристаллы холестерина не способны поступать с током желчи в кишечник до процесса трансформации их в камни. Уменьшение сокращения желчного пузыря возникает вследствие ряда факторов: изменения в процессах иннервации, которые осуществляют контроль за опорожнением желчного пузыря; нарушение гормональной регуляции; воздействие холестерина на гладкую мускулатуру стенки желчного пузыря. Вместе с тем, вклинивание конкремента в шейку желчного пузыря и пузырного протока служит причиной возникновения гипертензии в билиарном тракте. Последнее является основным и благоприятным условием для развития инфекционного процесса. Наряду с этим, желчные соли и желчные камни вызывают повреждение слизистой оболочки, которое вызывает изменения в проницаемости клеточных мембран. Это приводит к нарушениям коллоидного состояния желчи, вызывая асептическое воспаление в стенке желчного пузыря. При билиарной гипертензии происходит перерастяжение желчного пузыря, что способствует механическому сдавлению сосудов. Вместе с тем, возникновение нарушений микроциркуляции приводит к стазу крови в капиллярах, венулах и артериолах. Длительное существование гипертензии в билиарном тракте служит основой уменьшения гемоперфузии и развитием ишемии стенки желчного пузыря [22].

\section{К^ассификация}

Согласно МКБ -10 выделяют следующие виды холециститов [23]:

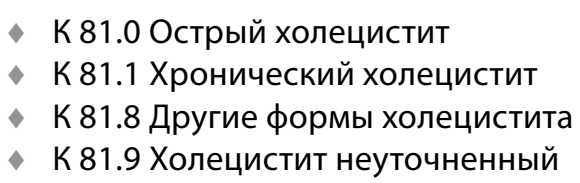

Патологоанатомическая классификация острого холецистита [23]:

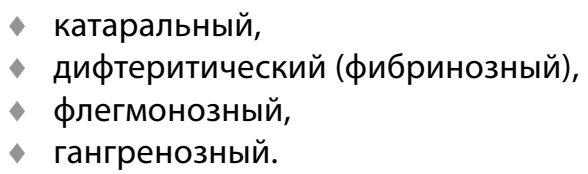

Согласно протоколу клинических рекомендаций POX по организации лечебно-диагностической помощи при остром калькулёзном холецистите и классификации Савельева В.С., 1986 г., выделяют следующие виды острого холецистита [23]:

1. Острый неосложненный холецистит:

А. Катаральный - увеличение желчного пузыря с утолщением, инфильтрацией его стенки и отеком слизистой оболочки. В просвете слизистый экссудат, с наличием лейкоцитов и эпителиальных клеток.

Б. Флегмонозный - желчный пузырь значительно увеличен и напряжён, покрыт фибринозной пленкой, стенки пропитаны гноем.

В. Гангренозный - некроз стенки желчного пузыря.

2. Острый осложненный холецистит:

А. Острый холецистит, осложненный перитонитом

Б. Острый холецистит, осложненный холангитом

В. Острый холецистит, осложненный панкреатитом

\section{КАИника}

Ведущим синдромом в клинической картине острого калькулёзного холецистита является болевой. Последний характеризуется спастическими острыми выраженными болями в правом подреберье, которые могут иррадиировать в спину, эпигастральную область, надключичную область и правую лопатку. Данное состояние получило наименование печеночной или желчной колики. Возникновение желчной колики связано со спазмом сфинктерного аппарата билиарного тракта и как следствие развитием билиарной гипертензией. Последняя приводит к довольно быстрому увеличению размеров печени и растяжению глиссоновой капсулы, содержащей значительное количество ноцирорецепторов. Вместе с тем, очаг болей расположен в точке Кера, расположенной на пересечении наружного края правой прямой мышцы живота и края реберной дуги. Ряд провоцирующих агентов (алкоголь, употребление жирной и/или острой пищи, стрессовые состояния) приводят к возникновению желчной колики $[24,25,26]$. 
Наряду с болевым синдромом возникает и диспепсический, который проявляется тошнотой; многократной рвотой, постепенно приобретающей характер рвоты с желчью; изжогой.

Синдром интоксикации характеризуется возникновением субфебрильной температуры, головными болями, чувством недомогания, тахикардией, сухостью кожных покровов, отсутствием аппетита, болями в мышцах. Наряду с этим, необходимо отметить, что повышение температуры прямо пропорционально связано с клиническим вариантом острого холецистита. Так при ка- таральном холецистите температура колеблется в пределах $37-38^{\circ} \mathrm{C}$, а при деструктивных формах достигает цифр $>38^{\circ} \mathrm{C}$. При наличии гнойного содержимого в просвете пузыря (эмпиема) или развитии перивезикального абсцесса наблюдается подъем температуры до гектических цифр с эпизодами падения и вновь подъема, что сопровождается выраженной потливостью.

Знание этиопатогенеза и клиники острого калькулёзного холецистита, позволит своевременно заподозрить данное заболевание и выработать необходимый диагностический и лечебный алгоритмы.

\section{ЛИТЕРАТУРА}

1. Endo I. et al. Optimal treatment strategy for acute cholecystitis based on predictive factors: Japan-Taiwan multicenter cohort study. J Hepatobiliary Pancreat Sci. 2017; 24(8):492-493. https://doi.org/10.1002/jhbp.456

2. Csikesz N, Ricciardi R, Tseng JF, Shah SA. Current status of surgical management of acute cholecystitis in the United States. World J Surg. 2008 0ct;32(10):22302236. https://doi.org/10.1007/s00268-008-9679-5

3. Ревишвили А.Ш., Федоров А.В., Сажин В.П., Оловянный В.Е. Состояние экстренной хирургической помощи в Российской Федерации. Хирургия. Журнал им. Пирогова. 2019;3(1):88-97. https://doi.org/10.17116/hirurgia201903188

4. Yokoe M., Takada T., Strasberg S., Solomkin J.S. et al. TG13 diagnostic criteria and severity grading of acute cholecystitis. Hepatobiliary Pancreat Sci. 2013;20:3546. https://doi.org/10.1007/s00534-012-0568-9

5. Kimura Y, Takada T, Strasberg SM, et al. TG13 current terminology, etiology, and epidemiology of acute cholangitis and cholecystitis. J Hepatobiliary Pancreat Sci. 2013;20(1):8-23. https://doi.org/10.1007/s00534-012-0564-0

6. Натрошвили И.Г., Прудков М.И. Насколько активной должна быть хирургическая тактика у больных острым холециститом (по результатам проспективного многоцентрового исследования). Вестн.Росс. ун-та дружбы народов. Серия: Медицина. 2019;23(2):156-167. https://doi.org/10.22363/23130245-2019-23-2-156-167

7. Strasberg SM. Acute calcolous cholecystitis. N Engl J Med. 2008;358:2804-11. https://doi.org/10.1056/nejmcp0800929

8. Stinton LM, Myers RP, Shaffer EA. Epidemiology of gallstones. Gastroenterol Clin N Am. 2010;39(2):157-69. https://doi.org/10.1016/j.gtc.2010.02.003

9. Ansaloni L, Pisano M, Coccolini F, et al. 2016 WSES guidelines on acute calculous cholecystitis. World J Emerg Surg 2016;11(1):1-23. https://doi. org/10.1186/1749-7922-9-58

10. Loozen C.S., Kortram K., Kornmann V.N.N. et al. Randomized clinical trial of extended versus single-dose perioperative antibiotic prophylaxis for acute calculous cholecystitis. Br J Surg 2017;104:151-157. https://doi.org/10.1002/bjs.10406

11. Sutton A.J ., Vohra R.S, Hollyman M. et al. Cost-effectiveness of emergency versus delayed laparoscopic cholecystectomy for acute gallbladder pathology. British Journal of Surgery 2017; 104 (1):98-107. https://doi.org/10.3410/f.726865309.793550821

12. Strasberg SM. Acute calcolous cholecystitis. N Engl J Med. 2008;358:2804-11. https://doi.org/10.1056/nejmcp0800929

13. Stinton LM, Myers RP, Shaffer EA. Epidemiology of gallstones. Gastroenterol Clin N Am. 2010;39(2):157-69. https://doi.org/10.1016/j.gtc.2010.02.003

14. Ansaloni L, Pisano M, Coccolini F, et al. 2016 WSES guidelines on acute calculous cholecystitis. World J Emerg Surg 2016;11(1):1-23. https://doi. org/10.1186/1749-7922-9-58

15. Вильяр Дж., Саммерс С.М., Менчин М.Д. и др. Отсутствие камней в желчном пузыре при ультразвуковом исследовании исключает острый холецистит. J Emerg Med. 2015; 49 (4): 475-80. https://doi.org/1010.1016/j.jemermed.2015.04.037

16. Майстренко Н.А. Стукалов В.В. Холедохолитиаз: СПб.: ЭЛБИ-СПб, 2000; 288 с.

17. Дадвани С.А., Ветшев П.С., Шулутко А.М. Прудков М.И. Желчнокаменная болезнь: М.: ГЭОТАР-Медиа, 2009;176 с.

18. Руководство по хирургии желчных путей: 2 е изд. Под редакцией Гальперина Э.И., Ветшева П.С. М: Видар М.; $2009 ; 568$ c.

19. Steven M, Strasberg S.M. Acute calculous cholecystitis. N Engl J Med 2008;358:2804-2811. https://doi.org/10.1056/nejmcp0800929

20. Strasberg S.M. Clinical practice. Acute calculous cholecystitis. N Engl J Med 2008;358:2804-2811. https://doi.org/10.1056/nejmcp0800929

21. Steel P. A D., Brenner B.E. Acute Cholecystitis and Biliary Colic. Medsckape, 2017.

22. Okamoto K., Suzuki K., Takada T.et al. Tokyo Guidelines 2018: owchart for the management of acutefl cholecystitis. J Hepatobiliary Pancreat Sci (2018) 25:5572. https://doi.org/10.1002/jhbp.526

23. Мерсаидова К.И., Прудков М.И., Нишневич Е.В., Багин В.А., Тарасов Е.Е., Исакова Е.В. Лапароэндоскопические вмешательства при холецистохоледохолитиазе (техника Rendezvous). Хирургия. Журн. им Н.И. Пирогова, 2019; 7:36-41. https://doi.org/10.17116/hirurgia201907136

24. Yokoe M., Takada T., Strasberg S., Solomkin J.S. et al. TG13 diagnostic criteria and severity grading of acute cholecystitis. Hepatobiliary Pancreat Sci. 2013;20:3546. https://doi.org/10.1002/jhbp.457 
25. Королев Б.А., Пиковский Д.Л. Экстренная хирургия желчных путей. М.: Медицина, 1990; 240 с.

26. Eskelinen M., Ikonen J., Lipponen P. Diagnostic approaches in acute cholecystitis; a prospective study of 1333 patients with acute abdominal pain. Theor Surg 1993;8:15-20. https://doi.org/10.3109/00365529409092499

○ Яшнов Алексей Александрович ( alexyashnov@mail.ru ), Коновалова Ольга Геннадьевна,

Ханина Юлия Сергеевна, Бурцева Мария Александровна, Пассонен Екатерина Юрьевна.

Журнал «Современная наука: актуальные проблемы теории и практики»

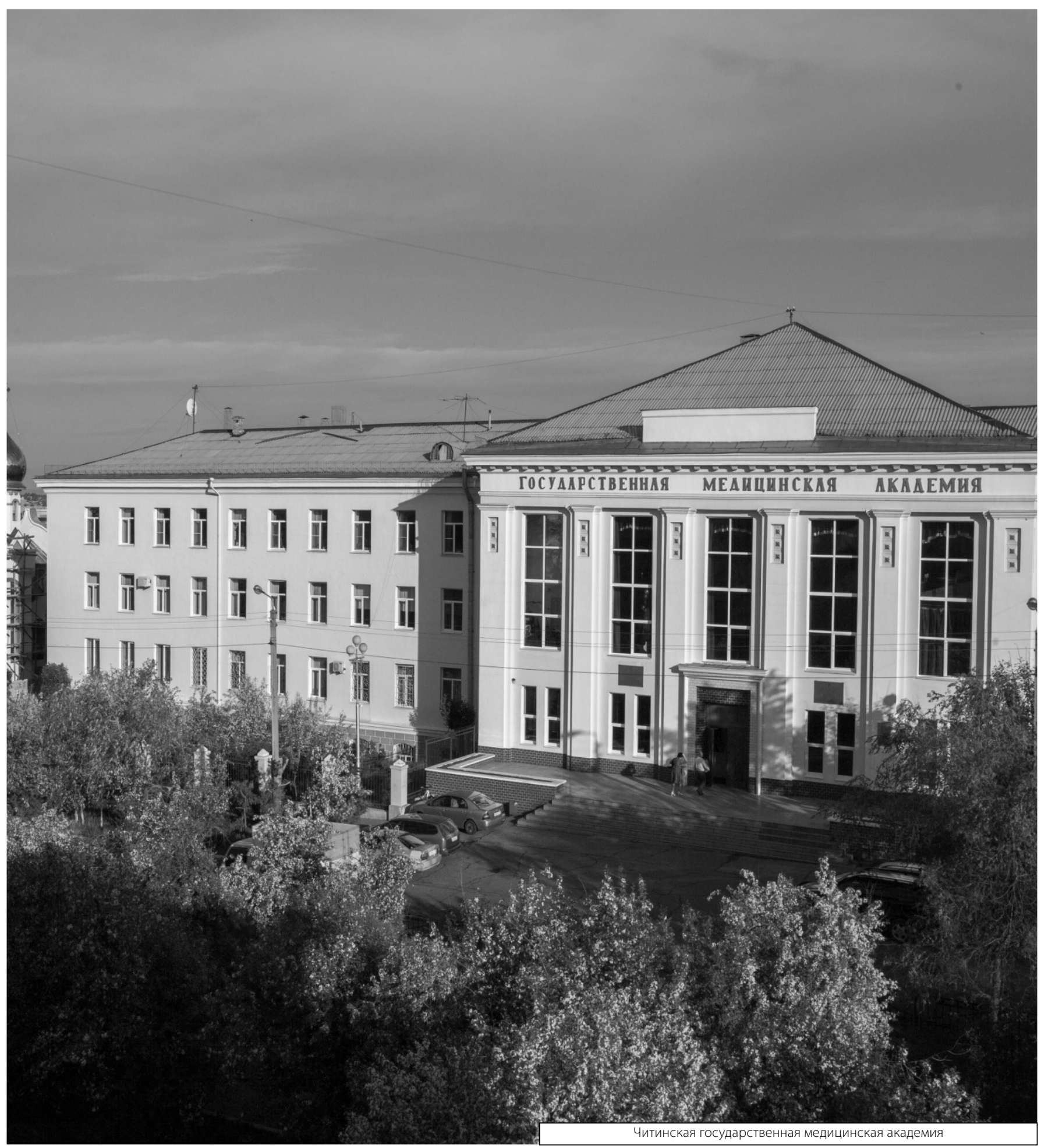

